\title{
WELFARE STATE AND JUDICIAL REVIEW. APROXIMACIÓN A UNA TEORÍA «POSIBLE» DEL ESTADO SOCIAL EN EL FEDERALISMO
}

\author{
VÍCTOR J. VÁZQUEZ ALONSO \\ Profesor Ayudante Doctor \\ Universidad de Sevilla
}

\section{SUMARIO}

I. Introducción: El experimento democrático del Welfare State.

II. Los Derechos Sociales y la excepción americana.

III. La teoría del Estado Social «posible».

IV. Reflexiones finales: El Judicial Review ante el Welfare State.

\section{INTRODUCCIÓN: EL EXPERIMENTO DEMOCRÁTICO DEL WELFARE STATE}

En un artículo reciente el profesor Koppelman alertaba sobre cómo las discusiones constitucionales se ven influidas, en ocasiones, por ciertas «leyendas urbanas», en torno a lo que admite o no admite el sistema político de un país. Koppelman se refería, en concreto, a la progresiva asunción de que en la Constitución Americana no cabe o, por lo menos, es conflictiva, una comprensión de los poderes públicos desde los parámetros propios del Estado de Bienestar ${ }^{1}$. Lo cierto es que la Constitución Americana no contiene disposiciones propias de lo que denominaríamos la constitución económica ni tampoco consagra derechos sociales o derechos de segunda generación de la forma en que lo hacen las constituciones europeas de postguerra. Es un texto que, en definitiva, no sale al encuentro del Estado Social. Sin embargo, pese a que la Constitución Americana no abre los brazos a una com-

1 ANDREW KOPPELMAN, «Bad News for Mail Roberts: The Obvious Constitutionality of Health Care Reform», 121 Yale Law Journal Online, April 26, 2011. 
prensión asistencial del Estado, lo cierto es que tampoco la prohíbe. Tal y como señalara el Juez Holmes en 1905, el constitucionalismo americano no abraza ningún modelo económico de forma excluyente ${ }^{2} \mathrm{y}$, en este sentido, ha de entenderse que el Welfare State constituye un experimento democrático que pueden decidir llevar a cabo las mayorías parlamentarias.

A este respecto, lo cierto es que, desde el New Deal en adelante, como tal experimento democrático, el Welfare State se ha abierto paso en el ordenamiento jurídico norteamericano, y lo ha hecho a través de un proceso en el que la institución del Judicial Review ha tenido una relevancia clave a la hora de marcar los límites de lo posible a las políticas públicas asistenciales a nivel tanto estatal como federal. En este sentido, este trabajo tiene el propósito de profundizar en la relación entre Welfare State y Judicial Review en el ordenamiento norteamericano, y aproximarse a los fundamentos constitucionales que han marcado el terreno de lo posible a las políticas de bienestar en el federalismo de los Estados Unidos.

Para ello, en un primer lugar, nos aproximaremos a uno de los elementos diferenciadores de este modelo, como es la ausencia de derechos sociales en la Constitución Federal, prestando especial atención al frustrado ensayo judicial de la Corte Warren de deducir derechos positivos o de prestación a partir de la Enmienda XIV de la Constitución. Posteriormente, estudiaremos el papel de la Corte Suprema durante el New Deal, y, en concreto, cómo ésta abandonó su comprensión estricta tanto del papel que el Estado puede desempeñar en la regulación de la actividad económica del país, como de los poderes conferidos al Congreso de los Estados Unidos, para permitir, a la postre, la consolidación de un Gobierno Federal con amplias competencias en materia económica. A este respecto, profundizaremos en la importancia de la lectura «centralizadora» de la Commerce Clause y la Welfare Clause de la Constitución Americana, que llevará a cabo la Corte Suprema desde los años treinta, a partir de la cual, se establecerán las premisas de un federalismo cooperativo, en el que la capacidad de persuasión financiera del Gobierno Federal será clave para la implantación de políticas asistenciales a nivel nacional. En otro apartado, se intentarán explicar las dificultades con las que, dentro de este modelo de Welfare State, marcado por el impulso federal, los jueces estatales aplican los derechos sociales que consagran las Constituciones de los Estados y de cómo, a nivel estatal, se va a abriendo paso la idea de reformular la función judicial cuando se trata de aplicar disposiciones que exigen políticas públicas que los jueces por sí mimos no pueden determinar. Finalmente, se insistirá en la dimensión moral que adquieren las categorías del federalismo dada la estrecha vinculación que existe entre éstas y la forma en la que se estructura el Welfare State en los Estados Unidos, intentando poner de manifiesto el necesario self restraint judicial que el principio democrático exige también en estos supuestos. 


\section{LOS DERECHOS SOCIALES Y LA EXCEPCIÓN AMERICANA}

En cierta medida, las diferencias originarias a través de las cuales se consagró el constitucionalismo a uno y a otro lado del Atlántico han ido en muchos casos matizándose de forma progresiva por la inercia de la lógica liberal y democrática que inspira ambas tradiciones. Sin embargo, puede considerarse que, de manera sobrevenida, la Constitución de los Estados Unidos, en contraposición con el constitucionalismo europeo de posguerra y con el propio constitucionalismo del continente americano, se ha quedado sola, como un texto excepcional, en tanto no consagra en ninguno de sus artículos derechos o principios propios de lo que denominamos el constitucionalismo social. Dicho de otra forma, pervive como marca distintiva del denominado «excepcionalismo americano», el hecho de que en su cultura jurídica los derechos sociales han permanecido siempre en el ámbito de la política, sin que a nivel federal hayan sido nunca sustraídos en grado alguno a la discrecionalidad del legislador, mediante su consagración constitucional.

Como señala Sunstein en un conocido trabajo en el que intenta dar respuesta y también matizar esta realidad, la primera razón de la especificidad americana en este ámbito es sencilla, y apunta a la propia longevidad de la Constitución americana, que sobrevive desde un tiempo en el que culturalmente la idea del constitucionalismo social no se encontraba ni siquiera en su estado embrionario. No obstante, a pesar de lo evidente que es esta realidad, no se podría desconocer que la interpretación del texto constitucional americano y, sobre todo, de las enmiendas que incorporan The Bill of Rights y la Due Process Clause, ha propiciado que ciertos ámbitos, los cuales en principio no disfrutaban de protección constitucional frente al legislador, hayan sido objeto de una construcción conceptual como derechos fundamentales, a través de la audacia interpretativa de la Corte Suprema ${ }^{3}$. Por lo tanto, la pregunta permanece y sería por qué esta audacia, o este activismo judicial, si se prefiere, no ha alcanzado también a promover la garantía constitucional de ciertos derechos de carácter social, íntimamente vinculados a la propia autonomía personal o incluso a la propia dignidad de la persona.

Hay quien ha apuntado, en este sentido, que la principal razón por la cual la interpretación judicial de la Constitución no ha explorado el camino de la eficacia de ciertos derechos sociales relacionados con el principio de igualdad de oportunidades, es una razón cultural. En la sociedad americana, la idea de dignidad habría estado integrada por toda una serie de facetas de la autonomía personal que responderían al concepto clásico de los derechos de libertad, y de la cual, no formarían parte ciertos derechos de carácter redistributivo, relacionados con la idea de igualdad en las condiciones materiales de vida ${ }^{4}$. De este modo, el germen genuinamente

3 Vid, CASS R. SUNSTEIN, «Why does the American...», op. cit., pp. 18-19.

4 Vid. NEOMI RAO, «American Dignity and Healthcare Reform», 35 Harvard Society for Law E Public Policy, Winter, 2012, pp.171 y ss; o el propio CASS R. SUNSTEIN, «Why does the American...», op. cit., pp. 17. 
liberal de la cultura política americana habría facilitado una lectura enfrentada de los principios de libertad y de igualdad material ${ }^{5}$, favorecida también por el rechazo al comunismo y su identificación con el antiamericanismo durante gran parte del siglo $\mathrm{XX}^{6}$. Creo que es más que probable que haya algo de exageración en estas tesis que presentan la preocupación política por las condiciones materiales de vida de los ciudadanos como un elemento en cierta medida extraño a la cultura norteamericana, y ello, no sólo porque resulta evidente el ethos cristiano ${ }^{7}$ y el componente republicano $^{8}$ de la cultura política americana desde sus orígenes, sino también porque, como sugiere el propio Sunstein, la historia demuestra que si bien ciertos líderes políticos como Theodore y Franklin D. Roosevelt o Lyndon Jonhson no eran precisamente susceptibles de ser considerados socialistas, sí dieron muestras claras de su preocupación social por la situación de desigualdad en la que vivían muchos americanos, impulsando importantes políticas federales dirigidas a mejorar las condiciones de vida de los ciudadanos ${ }^{9}$. Por lo tanto, tal vez, más que una patológica falta de interés por las condiciones materiales de vida de los más necesitados, lo que estaría presente en la cultura americana es la idea de que la Constitución Federal no ha de determinar en grado alguno la forma ni el umbral en el que han de garantizarse esas condiciones mínimas de vida ${ }^{10}$, sino que ha de ser el proceso político quien lo haga. Esta es, de hecho, la idea que subyacía en el proyecto de Roosvelt de avanzar en una Second Bill of Rights que hiciese realidad ciertos derechos de carácter social. Y es que esta Segunda Declaración de Derechos no presuponía la enmienda constitucional, ni siquiera su consagración integral o sistemática en una Ley Federal, sino que aspiraba a crear un «compromiso constitutivo» de las instituciones para llevar a cabo las políticas necesarias que hiciesen real un nuevo estatuto de bienestar ciudadano ${ }^{11}$. En definitiva, si de la tradición igualitaria que irrumpe con fuerza en la América de la Reconstrucción pueden distinguirse dos ámbitos diferenciados de lucha, el de la igualdad en derechos civiles y el de la igualdad de clase, sólo el primero y sólo en su

5 Vid. FREDERICK SCHAUER, «The Exceptional First Amendment», en The American Exceptionalism and Human Rights, p. 30, 2005.

6 Vid. THOMAS C. GEY, «Property and Need: the Welfare State and Theories of Distributive Justice», 28 Stanford Law Review, May, 1976, pp. 892-895.

7 Véanse, en este sentido, los clásicos: MARK DE WOLFE HOWE, The Garden and the Wilderness: Religion and Government in American Constitutional History, Chicago, 1965. ALEXIS DE TOCQUEVILLE, La democracia en America, Madrid, 2002, en especial, pp. 424-425.

8 En este sentido, son clásicos los trabajos de GORDON S. WOOD, The Creation of The American Republic, Virginia, 1998; BERNARD BAYLIN, The Ideological Origins of the American Revolution, Cambridge, Massachusset, 1992; J. G. A. POCKOC, «El mito de Locke y la obsesión con el liberalismo», en Historia e Ilustración, Madrid, 2002.

9 Vid. CASS R. SUNSTEIN, «Why does the American...», op. cit., p. 18

10 Vid. STEPHEN GARDBAUM, «The Myth and the Reality of the American Constitutional Exceptionalism», 107 Michigan Law Review, December 2008, pp. 446-448.

11 Vid. CASS R. SUNSTEIN, «Constitutive Commitments and Roosevelt's Second Bill of Rights: a dialogue. Cass R. Sunstein \& Randy E. Barnett», 53 Drake Law Review, 2005, p. 217. 
versión estrictamente liberal ha encontrado históricamente encaje constitucional ${ }^{12}$, mientras que el segundo ha permanecido siempre abierto a los procesos de decisión política.

\section{Los derechos sociales como political question}

Es fácil pensar que esta ausencia de un desarrollo interpretativo del derecho a la igualdad en clave social o prestacional, a la que hemos hecho referencia, esté relacionada con el propio radicalismo democrático que subyace en la cultura constitucional americana. Como explica muy bien Tushnet, hay algo en la sabiduría popular que nos dice que una Constitución que dé rango constitucional a ciertos derechos sociales, está al mismo tiempo abriendo la puerta a un modelo de Judicial Review potencialmente contramayoritario, en un terreno, además, que le es especialmente hostil a la justicia constitucional, al estar estrechamente vinculado a la política presupuestaría del Estado. Así, la complejidad económica de estas políticas redistributivas ${ }^{13}$ y su especial carga ideológica justificaría que, en este caso, la «última y la única palabra» sobre su implementación recayese de forma exclusiva en el proceso político $^{14}$, sin ninguna opción de revisión judicial ${ }^{15}$.

Ahora bien, pese a que estas objeciones democráticas a la eficacia de los derechos sociales parezcan evidentes, en realidad, y como dirían los persuasivos críticos de la objeción contramayoritaria a la justicia constitucional ${ }^{16}$, las mismas no dejarían, en cierta medida, de ser trasladables al propio ámbito de los derechos fundamentales clásicos, en los que la última palabra sobre las diferentes interpretaciones en conflicto que existan en una sociedad, sí es asumida por los jueces ${ }^{17}$. Quiero decir con ello que, si se piensa, tal vez no haya una diferencia tan abismal, en cuanto a su sesgo antidemocrático, entre que sea un Tribunal quien tenga la última palabra sobre cuestiones como el aborto, a que la tenga sobre el derecho a la educación, a la salud o a un mínimo de renta de subsistencia. Del mismo modo, como bien demostraron Holmes y Sunstein, no puede obviarse que la tutela de todos los derechos del Bill of Rights también conlleva costes financieros y

12 Vid. WILLIAM E. FORBATH, «Constitutional Welfare Rights: a History, Critique and Reconstruction», 69 Fordham Law Review, April 2001, pp. 1827-1829.

13 Vid. RICHARD POSNER, Economic Analysis of Law, 1977, pp. 503 y ss.

14 En este sentido, por todos, ROBERT H. BORK, «The impossibility of Finding Welfare Rights in the Constitution», 3 Washington University Law Quarterly, Summer, 1979, pp. 695-701.

15 Véase, ampliamente, JEFFREY OMAR USMAN, «Good Enough for Government Work: The Interpretation of Positive Constitutional Rights in State Constitutions, 73 Albany Law Review, 2010, pp. $1497-$ 1501; CASS R. SUNSTEIN, «Why does the American...», op. cit., pp. ; MARK TUSHNET, «Social Welfare Rights and the Forms of the Judicial Review», 82 Texas Law Review, june, 2004, pp. 1898-1903.

16 De manera exhaustiva, sobre este debate en la doctrina americana, véase el trabajo de DIEGO MORENO RODRÍGUEZ ALCALÁ, Control judicial de la ley y derechos fundamentales, Madrid, 2011.

17 Véase, en este sentido, MARK TUSHNET, "Civil Rights and Social Rights: The Future of the Reconstruction Amendments, 25 Loyola Law Review, 1992, pp. 1211-1216; JEREMY WALDRON, «Liberal Rights: Two Sides of the Coin», in Liberal Rights 1, 1993, p. 6; DIEGO MORENO RODRÍGUEZ ALCALÁ, Control judicial de la ley... op. cit., en especial, pp. 241 y siguientes. 
que cualquier decisión moral sobre los mismos implica a su vez una decisión de carácter redistributivo. En definitiva, la propiedad, el proceso debido, la libertad religiosa o de expresión, son derechos que también son caros, y su grado de eficacia está en gran medida condicionado a la inversión estatal en los mismos ${ }^{18}$.

No obstante, frente a esta idea de que la eficacia judicial de los derechos es siempre problemática desde el punto de vista democrático y, en último término, dependiente de la existencia de recursos públicos, siempre podrá alegarse que estas objeciones democráticas y presupuestarias adquieren una intensidad propia cuando se trata de dar eficacia constitucional a los derechos sociales. Hacer de estos derechos, derechos eficaces «aquí» y «ahora», es algo que difícilmente pueden hacer los jueces, si no es sobre la base de toda una serie de decisiones previas de carácter estrictamente político. Los jueces, en definitiva, no pueden edificar el Estado Social desde la Constitución. Sin embargo, lo que no parece imposible es que, en una sociedad bien ordenada y donde se asuma una cierta cultura del estado del bienestar, los jueces, de forma más modesta, sí puedan tener una función en la consolidación de esta cultura moral de los derechos sociales, deduciendo del texto constitucional ciertos límites o estándares de racionalidad cuando se trate de legislar sobre cuestiones que afectan directamente a las condiciones materiales de vida de los ciudadanos; o bien, en otros supuestos, imponiendo obligaciones mínimas a los poderes públicos, a la hora de proveer determinados bienes sociales. En este sentido, nos debe de seguir llamando la atención el hecho de que, si bien la Corte Suprema Americana se ha adentrado en complejos debates morales para los que en principio -o por lo menos, no de una manera evidente- no estaba legitimada por la Constitución, no lo ha hecho en cambio en un debate de igual calado moral, como es el relacionado con las condiciones materiales mínimas que deben deducirse del propio concepto de ciudadanía. Así, el activismo judicial, tan propio de algunos periodos de la historia de los Estados Unidos, no ha dejado una teoría de los derechos sociales como derechos constitucionales en la jurisprudencia norteamericana. Sin embargo, no puede decirse que no haya existido esta tentativa teórica y lo cierto es que, como veremos a continuación, los jueces de la Corte Warren ya habían apuntado este camino durante la década de los sesenta, esbozando una teoría posible de los derechos sociales en la Constitución americana.

\section{Una teoría imposible de los derechos sociales}

La jurisprudencia que vamos a analizar es, en puridad, un ensayo judicial exploratorio y frustrado, y, por ello, hay algo de arqueología constitucional en la lectura de estas decisiones. No obstante, su importancia creo que resulta capital, y ello, en tanto se trata de la única tentativa dentro de la Corte Suprema americana de proyectar los valores igualitarios de la Enmienda XIV de la Constitución sobre

18 STEPHEN HOLMES y CASS R. SUNSTEIN, El costo de los derechos. Por qué la libertad depende de los impuestos, 2011, Madrid, en especial, p. 69 y ss. 
desigualdades de carácter material. En definitiva, estamos ante un intento judicial de esbozar una teoría posible de los derechos sociales, a partir de una Constitución de marcado carácter liberal, que en buena medida demuestra que el papel del judicial review en la construcción del Welfare State en los Estados Unidos, podría haber sido otro.

Como no podría ser de otra manera, el punto de partida de esta jurisprudencia se sitúa en la igualdad y, concretamente, en una lectura de la Equal Protection Clause de la Enmienda XIV como límite frente a aquellas políticas públicas que excluyan a los más desfavorecidos de su ámbito de beneficiarios. Esta es la lógica que subyace tanto en Shapiro v. Thompson ${ }^{19}$ como King v. Smith ${ }^{20}$, dos decisiones en las que la Corte esboza un concepto de pobreza como categoría sospechosa de discriminación, de tal forma que, cualquier exclusión de los más desfavorecidos de los beneficios sociales prestados por el Estado, debía de superar un juicio estricto de constitucionalidad a través del cual se constatase la existencia de un interés estatal apremiante para dicha exclusión. Obviamente, esta jurisprudencia no abría la puerta, en sentido propio, a la judicialización de los derechos sociales como derechos constitucionales, y es que, sólo ante la existencia de un tratamiento desigual o arbitrario, el derecho ofrecía remedios para extender un determinado beneficio social, cuya previa y primera implementación, no lo olvidemos, no era una exigencia constitucional, sino que formaba parte de la discrecionalidad del legislador.

Sin embargo, no puede subestimarse esta teoría incipiente o larvada de los derechos sociales que esboza la Corte Warren. Y ello, no sólo porque la misma servía para constreñir la forma en la que el legislador debía de desarrollar determinadas políticas públicas -sin excluir a los más desfavorecidos- sino también porque, desde un punto de vista exclusivamente procesal, abría la puerta a que los ciudadanos pudieran reclamar desde la Constitución determinadas prestaciones sociales a los

19 Shapiro v. Thompson, 394 U. S. 618 (1969) En este caso, la Corte Suprema determina que es contrario a la libertad de movimientos entre los estados -el denominado derecho a viajar reconocido por Constitución- el excluir a una familia de los beneficios públicos que dada su situación de carencia le corresponderían, por el hecho de que el solicitante no cumplía con el requisito de llevar más de tres años residiendo en el Estado. A pesar de que es la vulneración del denominado derecho a viajar la que constituye la ratio recidendi del caso, la Corte abunda en la idea de que la Equal Protection Clause impide a los estados distribuir los beneficios del Estado del Bienestar en función de las contribuciones fiscales que hayan hecho los ciudadanos con anterioridad tal y como había defendido el Estado y en la necesidad de invocar un interés público para restringir el acceso a los programas sociales aquellas personas que se encuentran una situación de especial precariedad económica.

20 En King v. Smith, 392 U. S. 309 (1968) la mayoría de los jueces de la Corte sostuvo que el Estado de Alabama no podía excluir a una familia de beneficios previstos bajo un programa federal de ayuda a las familias con hijos dependientes, por el hecho de que la madre, viuda, mantuviera una relación sentimental con un hombre que eventualmente acudía a la casa familiar. El programa federal establecía como beneficiarias a las familias donde el padre se encontrase ausente y el Estado de Alabama había interpretado que no eran, por lo tanto, merecedoras de estas ayudas las familias en las que de facto había una presencia adulta masculina. A través de un razonamiento en el que la Corte sienta parte de las bases teóricas del federalismo cooperativo, la sentencia rechaza que la legislación federal permita esta interpretación restrictiva a los Estados, recordando el necesario compromiso de todas las agencias estatales con la erradicación de la pobreza y la necesidad de esgrimir un interés estatal apremiante para excluir a las personas que se encuentren en esta situación de los beneficios ofrecidos por el Estado. 
poderes públicos. La lucha por subvertir las desigualdades sociales encontraba así un cauce judicial más allá del ámbito del derecho de sufragio ${ }^{21}$ y el derecho a la asistencia letrada ${ }^{22}$, únicos contextos en los que hasta entonces la Corte había entendido que la Constitución no admitía que la falta de medios materiales pudiese constituir un motivo legítimo para condicionar el ejercicio de ciertos derechos.

Del mismo modo, al amparo de estas sentencias, la Corte espolea, en términos puramente constitucionales, un debate moral sobre la eficacia de los derechos sociales al cual pronto la doctrina académica va a salir al encuentro ${ }^{23}$. De hecho, en la doctrina americana de finales de los sesenta y principios de los setenta se consolida un sector doctrinal que se esfuerza por deducir verdaderos derechos sociales constitucionales en beneficio de los más desfavorecidos. Es obligado citar aquí la obra del profesor Michelman quien, a finales de los sesenta, en un conocido trabajo publicado en la Harvard Law Review, defendió el fundamento constitucional de ciertos derechos de prestación, partiendo, no del presupuesto de la existencia de un trato desigual por parte del Estado, sino de la obligación de garantizar un mínimo de protección de las necesidades básicas. La obra de Michelman asume, en este sentido, una interpretación republicana de la Constitución para sostener que la pobreza, la falta de acceso a determinados recursos básicos como la comida, la educación o el tratamiento médico, es en sí misma una desigualdad económica que repugna los valores que encarna el propio texto constitucional, en tanto impone una barrera a la plena participación del ciudadano en la comunidad política ${ }^{24}$.

21 Vid. Douglas v. California, 372 U. S. 353 (1963) donde la Corte entendió que se había vulnerado el derecho a un proceso justo, al denegársele a un indigente la asistencia letrada que este solicitó para recurrir una primera sentencia condenatoria. Para la Corte, esta decisión suponía una discriminación entre pobres y ricos, incompatible con la equidad que la Enmienda XIV de la Constitución impone a los procesos judiciales.

22 Es emblemática, en este sentido, la sentencia Harper v. Virginia Board of Elections, 383 U. S. 663 (1966) en la cual, la Corte revisa el precedente establecido en Breedlove v. Suttles, 302 U. S. 277 (1937) al declarar contrario a la Equal Protection Clause de la Enmienda XIV el establecimiento de requisitos económicos para el ejercicio del derecho de sufragio. La determinación del cuerpo electoral no puede basarse, según la Corte, en ninguna consideración relativa a la capacidad económica de los ciudadanos.

23 Es innegable en este sentido, la influencia de la obra de John Rawls y su recuperación del contractualismo como presupuesto de la justificación del compromiso constitucional con la igualdad material. En este sentido, tanto el principio de igualdad de oportunidades como el principio de diferencia, esbozados por Rawls en su Teoría de la Justicia, constituyen desde la década de los setenta y en el ámbito de la filosofía política, la tesis de referencia en lo relativo a la defensa de las políticas públicas de redistribución de la riqueza, y por ello también, el blanco de las críticas de la literatura libertaria americana. Vid. JOHN RAWLS, A Theory of Justice, Cambribge, 1971, en especial, pp. 171 y ss. Entre estas críticas libertarias a las que se hacía mención, es conocida la influencia de la obra de JAMES BUCHANAN, The limits of liberty. Between Anarchy and Leviathan, Chicago, 1975 y ROBERT NOZICK, Anarchy, State and Utopia, Osford, 1974. En la doctrina española existe un detallado estudio de la crítica de estos autores a la obra de Rawls de MIGUEL ÁNGEL RODILLA, Leyendo a Rawls, Salamanca, 2006, pp. 107-167.

24 Vid. FRANK J. MICHELMAN, «On Protecting the Poor Through the Fourteenth Amendment», 83 Harvard Law Review, 1969, pp. 7 y ss; "Welfare Rights in a Constitutional Democracy», 3 Washington University Law Quarterly, 3 Summer, 1979, pp. 650 y ss. Una lectura esclarecedora de las distintas etapas intelectuales de la obra de Michelman, la encontramos en la retrospectiva crítica que hace WILLIAM E. FORBATH, «Not so simple Justice: Frank Michelman on Social Rights», 1969 - Present, 39 Tulsa Law Review, pp. 597-638. 
Partiendo de otros presupuestos a la hora de interpretar la Constitución, autores como Reich llamaron la atención sobre la necesidad de esbozar un nuevo concepto constitucional de propiedad, tomando en consideración la circunstancia de que gran parte de los elementos del bienestar de los ciudadanos son proporcionados por el Estado y, por lo tanto, cualquier privación o restricción en las condiciones de disfrute de estos bienes, de esta «nueva propiedad», debía de estar sometida a las exigencias de Due Process Clause, del mismo modo que lo está la privación de la propiedad de los bienes muebles e inmuebles en su sentido clásico. Esta proyección de las exigencias del debido proceso sobre las medidas de privación o restricción de derechos sociales fue específicamente acogida por la Corte Suprema en su sentencia Goldberg c. Kelly ${ }^{25}$, donde la mayoría del Tribunal decidió anular la decisión del Estado de Nueva York de dar por terminada la prestación que recibía una familia, por no haberse permitido a las personas descalificadas tener conocimiento del procedimiento administrativo que dio lugar a esta decisión ni formular durante el mismo las alegaciones pertinentes. A través de este programa de asistencia el Estado proveía a las familias de fondos básicos para comida, vestimenta, alojamiento y asistencia médica. Unos bienes cuya entidad esencial implicaba, para la mayoría del Tribunal, que cualquier procedimiento para su supresión previese una oportunidad efectiva para defenderse. La proyección de la cláusula del debido proceso no requería, en este caso, de las garantías propias de un proceso judicial, pero sí que la administración diese audiencia a los interesados y permitiese a éstos practicar pruebas contradictorias con carácter previo a la decisión de rescindirles la ayuda ${ }^{26}$. Del mismo modo, y esto adquiere una importancia singular, la mayoría del Tribunal estimó que el interés estatal en mantener el equilibrio fiscal, no es argumento suficiente para rechazar la demanda de quien se ha visto privado de asistencia social sin haber tenido la oportunidad efectiva de defenderse. La mayoría del Tribunal en de Goldberg c. Kelly rechaza, en este sentido, que la objeción presupuestaria a los derechos de prestación pueda imponerse de una manera absoluta ${ }^{27}$.

Como se ha visto, de manera simultánea, la jurisprudencia de la Corte Suprema elaboró una teoría posible de los derechos sociales, a través de la proyección de la Equal Proteccion Clause y la Due Process Clause de la Enmienda Catorce, al ámbito de las políticas públicas del bienestar. Sin embargo, lo cierto es que el debate académico sobre la posible eficacia constitucional de los derechos sociales y, en concreto, sobre la traslación de la lógica del derecho a la igualdad al ámbito del estado del bienestar puede considerarse como algo residual o puramente especulativo a partir de 1973. La razón de ello es que, desde esa fecha, la discusión académica ya no puede nutrirse, ni siquiera a través de hipótesis o conjeturas interpretativas, de la práctica jurisprudencial, dado que la Corte Suprema ya había abrazado, de manera

25 Goldberg v. Kelly, 397 U. S. 254, (1970)

26 Goldberg v. Kelly, 397 U. S. 254, 266-269 (1970)

27 Goldberg v. Kelly, 397 U. S. 254, 270 (1970) 
hasta ahora definitiva, el principio de que en la Constitución no pueden encontrarse derechos positivos.

Como reconoce la mayor parte de la doctrina, la razón principal por la que este ensayo exploratorio de los derechos sociales no se consolida en el constitucionalismo americano, no se encuentra ni en la cultura ni en la dificultad de elaborar una teoría de los derechos sociales fundamentales, sino en algo tan sencillo como es la nominación de cuatro jueces por parte del presidente $\mathrm{Nixon}^{28}$, a partir de lo cual se formó en la Corte una mayoría decidida a cerrar el paso a cualquier interpretación de la Constitución que condujese a poder articular una de las ambiciones que se encontraban dentro de la agenda de ciertos sectores de la doctrina liberal ${ }^{29}$, y que era la de luchar judicialmente contra la desigualdad material y la pobreza a través de la Enmienda XIV.

La decisión que certifica este cambio jurisprudencial ${ }^{30}$ es, en gran medida, San Antonio Independent School Distric v. Rodriguez. En esta ocasión, la Corte tenía que juzgar la constitucionalidad de un programa educativo del municipio de San Antonio, en Texas, cuyo diseño financiero favorecía de forma ostensible a los alumnos de escuelas pertenecientes a aquellos distritos educativos en los cuales el nivel de renta era mayor. Los argumentos a partir de los cuales se atacaba la inconstitucionalidad del sistema, y que habían sido acogidos por la Corte de Distrito, eran básicamente dos. El primero, que existía un derecho fundamental a la educación y que cualquier diferenciación en las condiciones de su ejercicio habría de someterse a un estricto escrutinio, sin que en este caso la normativa pudiese superar ese juicio de constitucionalidad. En segundo lugar, bajo la base de la Equal Protection Clause, se consideraba que el criterio elegido para delimitar la inversión financiera del programa, que era el de discriminar los barrios con menos ingresos, podía asimilarse al de una «categoría sospechosa», de tal forma que la normativa tampoco podría superar un juicio de constitucionalidad a la luz de la Equal Protección Clause por discriminatoria. Pues bien, la Corte en una decisión adoptada por cinco a cuatro, cerró la puerta de forma taxativa a ambas argumentaciones. Es decir, que ni aceptó el argumento de que la pobreza podía considera-

28 Como es conocido, entre 1969 y 1972, el Presidente Nixon nombró a los magistrados Warren Burger, Harry Blackmun, Lewis Powell y William Rehnquist.

29 Vid. CASS R. SUNSTEIN, «Why does the American...», op. cit., pp. 18-22; JEFFREY OMAR USMAN, «Good Enough for Government Work...» op. cit., p. 1492; Vid. WILLIAM E. FORBATH, «Constitutional Welfare Rights: a History...» pp. 1856-1867.

30 Decimos «certifica» porque, con anterioridad a School District v. Rodriguez, la Corte ya había rechazado someter a un estricto escrutinio judicial aquellas políticas sociales en las que no se hubiese tomado en consideración el poder adquisitivo de las familias como un criterio de distribución de los beneficios estatales. Se trata de la sentencia Dandridge v. Williams. En este caso, se juzaba, un programa estatal de asistencia familiar, aprobado en el marco del programa federal de ayuda a las familias con hijos dependientes, en el que las autoridades del estado de Maryland no habían tomado en consideración el número de hijos de la familia a la hora de determinar la ayuda financiera prestada por el Estado, con lo cual, las familias más numerosas y, por lo tanto, con más necesidades, eran las menos beneficiadas por el programa. Para la mayoría del Tribunal en Dandridge, en este tipo de casos no está en juego ningún interés constitucional fundamental que exija la aplicación judicial de un Compelling Insterest Test. Vid. Dandridge v. Williams, 397 U. S. 471 (1970) 
se una categoría sospechosa; ni tampoco el que el derecho a la educación pudiese comprenderse como un derecho sometido a un estricto escrutinio, ya que éste no estaba consagrado de forma explícita en la Constitución. Para la mayoría de los jueces de aceptarse esa lógica deductiva, en base a la cual las necesidades sociales básicas se transformaban en derechos con eficacia directa ante los tribunales, ésta debería de extenderse también a ámbitos como el de la vivienda o el seguro médico, lo cual no era, en su opinión, sino una tentativa materialmente imposible ${ }^{31}$.

Bajo estas nuevas premisas, los esfuerzos judiciales y doctrinales de la década de los sesenta pasaban a ser, en cierta medida, materia de estudio de los historiadores del derecho, asumiéndose de forma general que «la Constitución no consagra ningún derecho positivo a la ayuda pública, incluso cuando esta ayuda sea necesaria para asegurar la vida, la libertad o la propiedad» ${ }^{32}$. Los derechos sociales a nivel federal podían considerarse en sentido propio, una political question, es decir una materia sobre la cual «los tribunales no pueden decidir sin faltar el respeto a la debida coordinación entre las distintas esferas de gobierno ${ }^{33}$. No obstante, como veremos en adelante, el hecho de que la Corte Suprema cerrara en falso su aproximación a la eficacia de los derechos sociales constitucionales no significa que el Estado Social dejase de ser una cuestión de interpretación constitucional, sino más bien que el debate constitucional se volviese a situar, no en los derechos sociales, sino en las políticas sociales y, con ello, en las categorías propias del federalismo, es decir, vinculado al reparto de poder entre el Gobierno de la Nación y los Estados que impone el federalismo americano.

\section{LA TEORÍA DEL ESTADO SOCIAL «POSIBLE»}

La Constitución americana no reconoce derechos sociales a sus ciudadanos ni tampoco consagra disposiciones propias de lo que denominamos la constitución económica. La implantación de políticas de bienestar en los Estados Unidos no ha sido, por lo tanto, la realización política de un programa constituyente sino una cuestión de carácter absolutamente democrático que irrumpe en las primeras décadas del siglo XX. En este sentido, el proyecto de consolidar un Welfare State en los Estados Unidos se enfrentó, en un principio, no tanto a la Constitución como a la propia interpretación que hizo de la misma la Corte Suprema desde comienzos

31 San Antonio Independent School District v. Rodriguez, 411 U. S. 1 (1973)

32 DeShaney v. Winnebago County Dep. of Soc. 489 U. S. 189, 196 (1989) Creo que puede resultar ilustrativa de la forma en la que el Tribunal desvincula la dimensión negativa de los derechos del compromiso económico del Estado con su eficacia, la jurisprudencia de la Corte Suprema sobre el aborto. Así, si bien, como es conocido, la mayoría del Tribunal consideró en Roe $v$. Wade que el derecho a la intimidad ampara constitucionalmente la decisión de abortar de una mujer, en reiteradas ocasiones ha negado que en virtud de ello los poderes públicos hayan de financiar este tipo de intervenciones. Véase, en este sentido, Maher v. Roe, 432 U. S. 464 (1977) Beal v. Roe, 432 U. S. 438 (1977) Poelker v. Doe 432 U. S. 519 (1977) Harris v. McRae, 448 U. S. 297 (1980)

33 Baker v. Carr, 369 U. S. 186 (1962) 
del siglo XX hasta finales de los años treinta, durante la conocida era Lochner, y que estuvo marcada por una compresión radicalmente liberal del papel del Estado en la economía y, a su vez, muy restringida en la interpretación de los poderes conferidos al Congreso, tanto para regular el comercio interestatal como para proveer el bienestar de los ciudadanos de la Nación. Es decir, en una lectura estrictamente dual del federalismo. La superación de ambos paradigmas, unida a una nueva comprensión fiscal del federalismo avalada por la Corte Suprema, constituirán, como se intentará explicar en adelante, los presupuestos que hacen viable lo que podemos denominar cómo una teoría posible del Estado Social en los Estados Unidos.

\section{La superación del paradigma del darwinismo social}

Como decíamos, uno de los pilares de la jurisprudencia Lochner era una lectura estrictamente liberal de la Constitución americana en lo relativo a las posibilidades de regular el mercado de trabajo en cualquier nivel de gobierno. Esta lectura liberal del texto constitucional se sustentaba en una proyección de la Due Process Clause al ámbito de las relaciones contractuales, a través de la cual, todo intento del Estado de legislar sobre las condiciones laborales era declarado contrario a la Constitución por suponer una injerencia en la libertad contractual. El gobierno de los jueces, como muy bien explicase Lambert, se erigió durante casi cuarenta años en un muro infranqueable frente a cualquier intento por parte de los estados de implantar una legislación social en materia laboral ${ }^{34}$. Así, desde la propia Lochner v. New York de $1905^{35}$, en la cual la Corte Suprema declaró contraria a la cláusula del debido proceso una ley del Estado de New York que limitaba el número máximo de horas de trabajo semanales de los panaderos; hasta la sentencia Morread $v$. New York de 1936, donde igualmente declaró contraria a la Constitución una ley que establecía el salarío mínimo en este mismo Estado, la Corte Suprema frenó todos los intentos legislativos de avanzar en la regulación de las condiciones de trabajo. De este modo, y sin dejar de ser paradójico, al amparo de la Enmienda XIV, la cual sólo se comprende desde el contexto de la Reconstrucción y que debe su origen y su legitimidad moral a la lucha contra la esclavitud, la Corte Suprema llevó hasta los últimos extremos una interpretación de la Constitución, insensible a cualquier

34 El enfrentamiento entre el Gobierno Federal y la Corte Suprema marcó especialmente la política americana de los primeros años de la década de los treinta. Gran parte de la legislación social del Congreso, entre ellas normativas tan importantes desde el punto de vista político como la Ley de Recuperación Industrial, Schechter Poultry Corporation v. United Status 295 U. S. 495 (1935), y la Ley de Ajuste Agrario, Butler v. United States, 297 U. S. 1 (1936), fueron neutralizadas por la Corte Suprema en base a las normas constitucionales de distribución del poder entre la Federación y los Estados. Pero la belicosidad de la Corte Suprema no solo alcanzó a las políticas sociales diseñadas a nivel federal, sino también estatal. Por ejemplo, en Morehead v. New York ex rel. Tipaldo, 298 U. S. 587 (1936), la Corte Suprema declaró que la Ley de Salario Mínimo de New York, era contraria a la Cláusula del Proceso Debido de la Enmienda XIV de Constitución, al restringir la libertad contractual de empresarios y trabajadores. Vid. ÉDUARD LAMBERT, Le gouvernement des juges et le lutte contre la legislation social aux États-Unis, Paris, 2004, en especial, pp. 51-59.

35 Lochner v. New York, 198 U. S. 45 (1905) 
proyecto de igualdad material, y que, en cierta medida, desde su radical liberalismo económico, promovía una suerte de darwinismo social, garantizando la total ausencia de intervención estatal en la economía ${ }^{36}$. Esta fue precisamente la crítica que hizo el Holmes en su corto pero emblemático voto particular a la opinión de la mayoría en Lochner $^{37}$, a la cual acusa de otorgar la autoría de la Enmienda XIV a Mr. Herbert Spencer y a sus ideas darwinistas sobre el libre mercado ${ }^{38}$. Para Holmes, la Corte Suprema había asumido algo que en ningún caso podía deducirse de la Constitución y era que ésta contenía, y con ello exigía, una determinada regulación de la economía del país.

Lo cierto es que la literatura sobre la Lochner Era ha sido ingente en la Academia Norteamericana. Algunos autores como Guillman han insistido en que tras esta línea jurisprudencial, más que una defensa judicial de un determinado modelo económico, se escondía un interpretación de la Enmienda Catorce contraria a cualquier tipo de legislación de clase ${ }^{39}$. Sunstein, en su día, interpretó la doctrina Lochner como una defensa judicial de la neutralidad del Estado frente a la sociedad y de la ausencia de cualquier tipo de intervención pública ${ }^{40}$. Por otro lado, desde que la historia constitucional adquirió actualidad procesal en la doctrina americana de manos del originalismo, no han sido extrañas las lecturas revisionistas de la Lochner Era, queriendo ver en sus fundamentos teóricos una correcta interpretación maximalista de las libertades de los ciudadanos. En este sentido, David E. Berstein, uno de los autores más perseverantes a la hora de denunciar la injusta demonización ideológica de la Lochner Era, ha querido ver en esta jurisprudencia una impronta libertaria, e incluso el antecedente intelectual de decisiones judiciales radicalmente favorables a la autonomía del individuo, como la propia protección constitucional del derecho al aborto en tanto manifestación del derecho a la intimidad que esboza la Corte Suprema en Roe v. Wade ${ }^{41}$.

En cualquier caso, y pese a que el debate doctrinal en torno a Lochner parece interminable, desde la perspectiva de la construcción del Welfare State en América, lo relevante es que la Corte Suprema va a abandonar sin retorno esta comprensión radicalmente liberal de las relaciones laborales en la conocida decisión West Coast Hotel c. Parrish ${ }^{42}$. Para ello la Corte Suprema americana revisa el propio concepto

36 Véase, ampliamente, BENJAMIN TWISS, Lawyers and the Constitution: How Laissez Faire came to the Supreme Court, Princeton, 2001.

37 Por los efectos y la influencia que este voto particular iba a tener el futuro, un autor como Postner llega a afirmar que se trata de «la opinión judicial más importante de los últimos cien años» Vid. RICHARD A. POSTNER, Law and Literature, Cambridge, Massachusetts, 1998, p. 271.

38 La obra a la que, en concreto, parece aludir Holmes, es: HERBERT SPENCER, Social Statics: The Conditions Essential to Human Happiness Specified, and the First of Them Developed

39 Vid. HOW ARD GILLMAN, The Constitution Besieged: The Rise \& Demise of Lochner Era Police Powers Jurisprudence, 1993, en especial, pp. 61-86.

40 Vid. CASS S. SUNSTEIN, «Lochner's Legacy» 87 Columbia Law Review, 1987, pp. 873-918.

41 Véase, en extenso, DAVID BERSTEIN «Lochner Era Revisionism, Revised: Lochner and the Origins of Fundamental Rights Constitutionalism» Georgetown Law Journal, Vol. 82, No. 1, 2003.

42 West Coast Hotel c. Parrish 300 U. S. 379 (1937) El mismo autor dedica dos extensas monografías al studio de esta época: Regulations, and the Courts from Reconstruction to the New Deal (Duke University 
de libertad que hasta entonces había mantenido y que comprendía la autonomía contractual como una de sus manifestaciones por naturaleza casi absoluta o incontrolable. A partir de esta sentencia la Corte entenderá que, en el ámbito laboral, las restricciones legislativas a la libertad contractual que tengan como objeto proteger determinados intereses básicos de la comunidad, como lo son la salud, el bienestar o la seguridad de los ciudadanos, no son contrarias a las exigencias del debido proceso y están, por lo tanto, amparadas por la Constitución. Tal y como había sugerido el Juez Holmes en West Coast Hotel c. Parrish, la Corte, en esta ocasión, no presta su prestigio a ningún modelo económico, sino que asume que la Constitución Americana presenta un alto grado de neutralidad con respecto a cual ha de ser la política económica del país, y que, por lo tanto, ha de ser el proceso político el que lo determine ${ }^{43}$. En este nuevo contexto judicial es en el que el New Deal encuentra un camino abierto para realizar aquello que Roosevelt había años antes anunciado durante su conocido discurso en el Commonwealth Club de San Francisco: «Ha llegado el momento de una administración consciente. Desde mi punto de vista, la tarea del gobierno en su relación con las empresas es ayudar al desarrollo de un orden económico constitucional» ${ }^{44}$

\section{Welfare State y centralización política}

Es de sobra conocido que detrás de este cambio de doctrina judicial que hemos visto en West Coast Hotel se encuentra la audacia del presidente Roosvelt, quien presionó a los jueces de la Corte con la amenaza de enmendar la Constitución y modificar la composición del Tribunal Supremo para alterar sus fuerzas ${ }^{45}$. No obstante lo

Press, 2001 y Rehabilitating Lochner: Defending Individual Rights against Progressive Reform, University of Chicago Press, 2011. En ambos trabajos podemos encontrar una abrumadora bibliografía sobre las distintas posiciones existentes hoy dentro de la doctrina americana, en torno al significado de la Lochner Era.

43 Creo que vale la pena reproducir esta llamada a la autocontención judicial en materia económica que realiza Holmes en su voto particular:»Some of these laws embody convictions or prejudices which judges are likely to share. Some may not. But a constitution is not intended to embody a particular economic theory, whether of paternalism and the organic relation of the citizen to the State or of laissez faire». Lochner v. New York, 198 U. S. 45, 74 (1905) (Holmes dissenting)

44 Vid. The Public Papers and Adresses of Franklin D. Roosevelt, 13., vols., New York, 1938-1959. Citado por, DAVID M. KENNEDY, Entre el miedo y la Libertad. Los EEUU: de la Gran Depresión al fin de la Segunda Guerra Mundial (1929.1945), Barcelona, 2005, p. 447.

45 Frente al frente judicial contra la legislación social del New Deal, el Presidente Roosevelt promovió una compleja reforma de la Constitución dirigida a modificar la composición del Tribunal Supremo y así alterar sus fuerzas. Si bien, tal reforma no fue necesaria puesto que la mayoría del Tribunal cambió de orientación desde la «deserción» del Presidente Roberts del sector conservador, en West Coast Hotel c. Parrish 300 U. S. 379 (1937), donde una mayoría de cinco a cuatro votó esta vez a favor de la constitucionalidad de la Ley de Salario Mínimo que había aprobado el estado de Washington. Un gesto que a la postre sirvió para frenar la reforma ideada por Roosevelt y que los cronistas políticos lo perpetuaron para la historia bajo la frase «The switch in time that savednine» (una puntada a tiempo que salvo los nueve) Pero, al margen de esto, el cambio de voto del Juez Roberts significó un verdadero punto de inflexión en la jurisprudencia del Tribunal que, desde entonces, no solo abandono una visión estricta del papel del gobierno en la economía, basada en la Sustantive Due Process Clause, sino que también modificó radicalmente la comprensión que había mantenido de 
literario de este conocido relato, no debe obviarse que, principalmente, fue el estado de opinión creado en ese momento constitucional que fue el New Deal, el que determinó una nueva forma judicial de entender el papel que el Estado ha de desempeñar el Estado en la sociedad ${ }^{46}$. Un cambio de comprensión que, como explica en un libro reciente el profesor Katznelson, estuvo marcado en gran medida por el miedo que de forma transversal se instaló en la sociedad americana tras la Guerra, la Gran Depresión y el auge de los totalitarismos europeos ${ }^{47}$. Este miedo, no sólo va a modificar para siempre la idea del papel que han de desempeñar los poderes públicos en la economía y el bienestar de los ciudadanos, sino que, inevitablemente, afectará también a la propia comprensión del federalismo del sistema. Así, del mismo modo que, de forma progresiva, se había asumido que era necesario superar en el ámbito de las relaciones laborales, una comprensión radicalmente liberal de la Due Process Clause, se abrió paso la idea de que para llevar a cabo un desarrollo en clave social de la Constitución como el que inspiraba la agenda New Dealer, y dar respuesta a las propias necesidades de coordinación de una economía nacional en crisis, era necesario reinterpretar la categorías propias del federalismo a favor de los poderes del Congreso $^{48}$. Y es que, paradójicamente, después del impulso unionista que había significado la Guerra Civil y las posteriores enmiendas de la reconstrucción y, también, cuando las exigencias de una sociedad industrial se habían hecho más patentes, la Corte Suprema de los Estados Unidos había consolidado una doctrina muy restrictiva respecto de los poderes conferidos al Gobierno Federal. La revolución social del New Deal exigía también, en este sentido, una revolución constitucional ${ }^{49}$ centralizadora que se va a hacer realidad, no a través de la enmienda constitucional, sino, principalmente, a través de la nueva lectura que hace la Corte Suprema americana de la Commerce Clause, en base a la cual se superará el paradigma dual del federalismo, avanzando hacia un nuevo federalismo acuñado como cooperativo ${ }^{50}$.

Esta transformación radical en la comprensión constitucional de los poderes conferidos al Congreso se produce entre 1937 y los primeros años de la década de los cuarenta y tiene como punto de partida la sentencia $N L R B v$. Jones $\mathcal{E}$

los poderes conferidos al Gobierno Federal en la Constitución. Sobre la historia y la intrahistoria de la batalla mantenida por el Presidente Roosevelt con la Corte Suprema y, en general, sobre esta época en la política de los Estados Unidos es excepcional el trabajo, ya clásico de DAVID M. KENNEDY, Entre el miedo y la Libertad..., op. cit., pp. 389-419.

46 Vid. BARRY FRIEDMAN, The Will of the People: How Public Opinion Has Influenced the Supreme Court and Shaped the Meaning of the Constitution, New York, 2009, p. 205.

47 IRA KATZNELSON, Fear Itself: The New Deal and the Origins of Our Time, New York, 2013, en especial, pp. 27-96.

48 Véase, ampliamente, CASS R. SUNSTEIN, «Constitutionalism after New Deal», 101 Harvard Law Review, decembre, 1987, pp. 421 y ss; RICHARD B. STEWARD, «Evaluating New Deal», 22 Harvard Journal of Law and Public Policy, pp. 239-240.

49 Vid. BRUCE ACKERMAN, We the People. Foundations, 1991, pp. 34-57.

50 Vid. EDUARD CORWIN, «National- State Cooperation. Its present Possibilities», 46 The Yale Law Journal, 1937, pp. 599 y ss; ANTONIO LA PERGOLA, «El federalismo cooperativo. Entra en escena el New Deal», en Los nuevos senderos del Federalismo, Madrid, 1994, p. 290 
Laughlin Steel ${ }^{51}$, en la cual, la Corte Suprema validará la constitucionalidad de una legislación federal sobre relaciones laborales que el Congreso había aprobado bajo el poder que le confiere la Constitución para regular el comercio interestatal. Hasta este momento, la Corte Suprema había sostenido que la Commerce Clause no constituía un fundamento legítimo para la regulación federal de actividades que no podían considerarse como intercambio comercial en sentido estricto; ni tampoco de aquellas cuyos efectos en el comercio interestatal fueran sólo de carácter indirecto. De esta forma, la jurisprudencia de la Corte Suprema había excluido, en concreto, que el Gobierno federal pudiera intervenir legislativamente en las condiciones laborales de producción de los productos manufacturados ${ }^{52}$, con lo cual, el estatuto jurídico de los trabajadores era una cuestión que, desde el punto de vista constitucional, debía de resolverse en el ámbito interno de los estados. Sin embardo, a partir de NLRB v. Jones $\mathcal{E}$ Laughlin Steel, la mayoría de los jueces del Tribunal van a interpretar que cualquier actividad económica intraestatal que tenga una relación sustancial con el comercio entre estados podrá ser regulada por el Congreso Federal en base a los poderes que la Constitución le otorga a través de la Commerce Clause.

Esta nueva doctrina significaba, en la práctica, que una ley federal podía normalizar las condiciones de trabajo en las empresas privadas, estableciendo un estatuto básico para sus trabajadores. En principio, el poder del Congreso alcanzaba únicamente a la regulación de las condiciones laborales de fabricación de aquellos productos que estaban destinados al comercio entre los Estados pero pronto, en 1941, con ocasión de la sentencia United States v. Darby ${ }^{53}$, la Corte Suprema reafirmará el poder del Congreso para regular también las condiciones laborales de producción de aquellos productos destinados únicamente al comercio intraestatal. Es más, para la Corte, el poder del Congreso bajo la Commerce Clause alcanza también a la regulación de aquellas actividades individuales que ni siquiera estén destinadas al comercio ${ }^{54}$, siempre y cuando pueda entenderse que la suma agregada de las mismas pueda tener un efecto sustancial en la economía nacional ${ }^{55}$.

El impacto centralizador de la nueva interpretación de la Commerce Clause se va a ver potenciado por el juego conjunto de esta cláusula constitucional con la Necessary and Proper Clause, en virtud de la cual, el Congreso puede aprobar aquella legislación que sea necesaria y adecuada para ejecutar políticas que se encuentren en el ámbito material de alguno de los poderes que la Constitución de los Estados Unidos otorga al Gobierno Federal. Como es conocido, la primera in-

51 National Labor Relations Board v. Jones E Laughlin Steel Corporation, 301 U. S. 1 (1937)

52 Como resumen de esta línea jurisprudencial, puede verse, por todas, Schechter Poultry Corporation v. United States 295 U. S. 495 (1935)

53 United States v. Darby, 312 U. S. 100 (1941)

54 «...the power of Congress to regulate interstate commerce extends to the regulation through legislative action of activities intrastate which have a substantial effect on the commerce or the exercise of the Congressional power over it» United States v. Darby, 312 U. S. 100, 121 (1941)

55 Wickard v. Filburn, 317 U. S. 111 (1942) 
terpretación que hace la Corte Suprema de esta cláusula se remonta a la emblemática sentencia del Juez Marshall en McCulloch v. Maryland, en la cual, el Tribunal abraza las tesis de Hamilton, favorables a leer de forma extensiva los poderes que la Constitución de los Estados Unidos confiere al Gobierno Federal, de cara a poder garantizar la unidad económica de la Nación, a través, en este caso, de la creación de un segundo Baco Nacional. Frente a esta lectura expansiva, Madison y Jefferson habían defendido una interpretación restrictiva de los poderes conferidos al Congreso bajo esta cláusula, basada en el presupuesto de que el concepto Necessary debía de entenderse como sinónimo de «indispensable» o «absolutamente necesario», de tal forma que no cualquier faceta del poder que pudiera vincularse de alguna forma a las competencias enumeradas a favor de Congreso en la Constitución, podría comprenderse cómo implícitamente conferida al Gobierno de la Nación ${ }^{56}$. Como se ha dicho, Hamilton, Secretario del Tesoro de aquel Gobierno, y su viejo aliado Federalista, el Juez Marshall, defendieron una lectura del término Necessary mucho más laxa, como sinónimo de «conveniente». Tal era, en su opinión, el uso popular que se hacía de este término que, en cualquier caso, no podría ser entendido en términos constitucionales como una exigencia de «absoluta necesidad». Esta última comprensión de la Necessary and Proper Clause fue la que al final se impuso, lo que implicaba admitir que el Congreso tenía un margen razonable para considerar qué medidas son convenientes para la ejecución de los poderes enumerados a su favor por la Constitución de los Estados Unidos. La amalgama de poderes implícitos, vinculados razonablemente al ejercicio de las competencias reservadas al gobierno central, debía de considerarse, por lo tanto, como facetas legítimas del poder conferido al Gobierno de la Nación por la Constitución.

En base a esta idea, desde McCulloch v. Maryland la Corte había avalado la constitucionalidad de aquellas normativas aprobadas por el Congreso de la Nación sobre ámbitos materiales en los cuales éste carecía de una competencia expresa, siempre y cuando fuese razonable la vinculación de estas facetas del poder a la consecución de determinados objetivos que la Constitución encomienda al gobierno central. Pues bien, la nueva comprensión de la Commerce Clause que desde 1937 va a afirmar la Corte Suprema, no solo incrementó el ámbito de políticas que el Congreso podía llevar a cabo bajo esta cláusula, sino que supuso también que, en virtud de la Necessary and Proper Clause, se entendiera que, de forma implícita, el Congreso

56 Admitir la tesis contraria, es decir, la tesis de los poderes implícitos significaría, en palabras de Madison, «que todo poder posible sería susceptible de ser legítimamente ejercido por el Gobierno Federal, y ello en todos los casos imaginables y sin ninguna limitación». Algo que, en su opinión, ponía en peligro el conjunto del sistema. Para Madison, en este sentido, era necesario distinguir entre «los poderes necesarios y adecuados para el gobierno de la Unión» y «los poderes necesarios y adecuados para ejecutar las competencias enumeradas a favor del Congreso Federal en la Constitución». La Necessary and Proper Clause únicamente otorgaría concretas facetas de gobierno en este segundo caso, es decir, solo cuando se trate de poderes derivados de la naturaleza misma del poder conferido al Gobierno Federal. Vid. RANDY E. BARNNETT, «The Original Meaning of the Necessary and Proper Clause», 6 University of Pennsylvania of Constitutional Law 183, November, 2003, pp. 188-196. 
estaba conferido de todos aquellos poderes que razonablemente pudieran entenderse adecuados para llevar a cabo las nuevas finalidades que la Commerce Clause hace descansar bajo el Gobierno Central con la nueva interpretación de la Corte. Todo esto sin olvidar que, en el ámbito de los poderes conferidos por la Constitución al Congreso, la ley federal, en virtud de la cláusula de supremacía, va a desplazar a la ley estatal.

Por lo tanto, desde la década de los cuarenta cualquier problema económico dejará de ser local cuando pueda constatarse que el mismo posee una relación sustancial con la economía y el comercio nacional; y, desde ese momento, el Congreso podrá llevar a cabo todas las medidas que considere necesarias y adecuadas para aportar una solución nacional a los problemas económicos de la Nación, siendo, en este sentido, muy limitado el juicio que la Corte Suprema puede hacer sobre la adecuación y la necesidad de las medidas aprobadas por el Congreso. Así, en la práctica, el respeto hacia el principio democrático se ha traducido en la aplicación judicial de un Rational Based Test especialmente deferente hacia los criterios en virtud de los cuales el legislador entendió que una determinada ley era adecuada o necesaria. No deja de ser indicativo, a este respecto, el hecho de que en una edición de su manual del año 1978 el profesor Tribe ${ }^{57}$ señalara que, desde 1937, era común la conciencia de que no es posible controlar judicialmente la acción del Congreso a través de los límites del federalismo y que por ello, la única garantía de los Estados era, tal y como defendían autores como Chopper ${ }^{58}$, casi exclusivamente política, es decir, a través de su participación en el debate legislativo por medio de sus representantes en el Senado. La centralización trajo consigo, en este sentido, una suerte de aceptación de la idea del federalismo como proceso, primando sus elementos dinámicos de lógica centralizadora, sobre una interpretación originalista o literal del reparto de poderes que hace la Constitución americana ${ }^{59}$.

57 LAURENCE H. TRIBE, American Constitutional Law, New York, 1978, p. 300.

58 JESSE H. CHOPER, Judicial Review and the National Political Process, A Functional Reconsideration of the Role of the Supreme Court, Chicago, 1980. Léase, por ejemplo, y sobre estas mismas premisas, la opinion de Blackmun en García v. San Antonio «Any substantive restraint on the exercise of Commerce Clause powers must find its justification in the procedural nature of this basic limitation, and it must be tailored to compensate for possible failings in the national political process, rather than to dictate a «sacred province of state autonomy» Garcia v. San Antonio Transit Authority, 469 U. S. 529 (1984)

59 Creo que, junto a esta deferencia democrática, influye también en la consolidación de una interpretación centralista de la Constitución, el prestigio moral que adquiere la acción legislativa del Congreso bajo la base de la Commerce Clause, durante la década de los sesenta y setenta. No hay que olvidar, en este sentido, que fue a través de esta cláusula cómo la Corte Suprema encontró un fundamento legítimo para la legislación en materia de derechos civiles que sirvió como respuesta federal frente a las Jim Crow Policies de los Estados del sur. Así, al contrario de lo que presagiara Madison, lo cierto es que desde la década de los treinta el progresivo debilitamiento de la idea original de que la de soberanía de los Estados, a favor de una comprensión fuerte de los poderes conferidos al Estado por la Constitución, lejos de amenazar las libertades de los ciudadanos, había sido el presupuesto para una ampliación de sus derechos civiles y, a su vez, para la implementación de políticas federales que reducían las desigualdades materiales en las condiciones de vida en todo el territorio nacional. 


\section{El Estado Social de la seducción financiera}

Sin necesidad de enmendar la Constitución, el New Deal dejó como legado una nueva compresión de los poderes del Congreso bajo la Commerce Clause que abrió las puertas a una regulación federal de la economía nacional, a través de la cual se afirmaron los principios reformadores básicos del Welfare State. Ahora bien, más allá de la regulación federal de las condiciones de producción, la consolidación del Estado Social requirió de una nueva comprensión, también centralizadora, del federalismo fiscal, en virtud de la cual el Congreso federal pudiese diseñar políticas de gasto sobre ámbitos asistenciales que históricamente habían permanecido bajo el poder de los Estados. Así, si el poder para recabar ingresos por parte del Gobierno se fortaleció a través de la aprobación de la Enmienda XVI de la Constitución americana, que permite al Gobierno Central gravar directamente la renta de los ciudadanos; la capacidad del Congreso para implementar políticas de gasto público y estímulo financiero, también va experimentar una nueva comprensión, pero no como consecuencia, en este caso, de una enmienda constitucional, sino a través de una interpretación extensiva del poder de gasto que confiere la General Welfare Clause de la Constitución al Congreso de los Estados Unidos ${ }^{60}$. Al igual que sucedía con la interpretación de la cláusula de comercio, desde la América temprana, las concepciones de Madison y Hamilton a cerca del alcance de los poderes conferidos al Congreso bajo la Welfare Clause, eran también en este caso antagónicas. En coherencia con su visión residual de los poderes conferidos al Congreso, para Madison, la capacidad de gasto del Gobierno de la Nación, únicamente alcanzaba a aquellos ámbitos en los que explícitamente la Constitución otorgaba un poder regulatorio al Congreso Federal. Contrariamente a éste, Hamilton defendió desde un principio una lectura mucho más laxa de los poderes del Congreso bajo la Welfare Clause, extendiendo el poder de gasto más allá de las facetas de gobierno reservadas por la Constitución al gobierno central ${ }^{61}$. Esta segunda lectura es la que finalmente se impone, y la misma tendrá consecuencias determinantes desde el New Deal en adelante, sirviendo de base para las denominadas grant-in-aid: transferencias financieras condicionadas de la federación a los estados, en virtud de las cuales, el gobierno federal conseguirá establecer políticas públicas de carácter asistencial en áreas en las que la Constitución no le reserva ninguna competencia legislativa. Las grantin-aid han constituido, en este sentido, el instrumento básico de cooperación en las relaciones intergubernamentales propias del federalismo americano del siglo $\mathrm{XX}^{62}$,

60 Concretamente, en su artículo primero, sección octava, la Constitucion consagra la General Welfare Clause en estos terminus: The Congress shall have Power To lay and collect Taxes, Duties, Imposts and Excises, to pay the Debts and provide for the common Defence and general Welfare of the United States; but all Duties, Imposts and Excises shall be uniform throughout the United States.

61 Sobre esta discusión véase United States v. Butler - 297 U. S. 1, $65-68$ (1936) y JOSEPH STORY, Commentaries on the Constitution of the United States 5th ed., Vol. I, $\$ 907$, quien constituye la referencia doctrinal de esta sentencia.

62 En la doctrina española contamos con importantes trabajos sobre el federalismo fiscal americano en los que se aborda en profundidad la evolución jurisprudencial en la interpretación de la Welfare Clause. Véan- 
disfrutando, desde pronto, del favor judicial. Y es que, desde la temprana sentencia Massachusetts v. Mellon, la Corte Suprema ha venido afirmando la adecuación a la Constitución de estos programas y, en concreto, a las exigencias de la Décima Enmienda que, como es sabido, garantiza que los poderes no delegados a los Estados Unidos por la Constitución, ni probibidos por ella a los estados, están reservados a los estados o al pueblo. La naturaleza contractual de estos programas de estímulo financiero ha constituido para la Corte una garantía de la indemnidad de los derechos de los estados, los cuales disponen de libertad para acceder a participar en los programas federales que exigen la implementación estatal de determinadas políticas públicas diseñadas a nivel federal, a cambio de constituirse en beneficiarios de determinadas partidas financieras ${ }^{63}$.

Lo cierto es que, sobre todo a partir de la década de los sesenta y del denominado «federalismo creativo» que caracterizó el proyecto de Great Society de Lihndon Jonhson, este mecanismo de seducción financiera ha constituido el pilar de todas las políticas asistenciales de Gobierno Federal y con ello del Welfare State norteamericano $^{64}$. Así, si bien la Constitución de los Estados Unidos en ningún momento exige que se equiparen las condiciones de vida entre los habitantes de los distintos estados, y muy probablemente, en el origen de la misma estuviera presente la idea de que sus habitantes votaran por los pies, premiando con el capital humano de la migración a aquellos estados donde el nivel de bienestar garantizado y la prosperidad fuera mayor; lo cierto es que, a través de lo que podemos calificar de experimento democrático, durante la segunda mitad del siglo XX, en la cultura política americana se ha asumido, por lo menos en parte, la idea de que «una Constitución que no organice un gobierno eficaz capaz de cobrar impuestos y gastar, fracasará a la hora de proteger ciertos derechos ${ }^{65}$. Del mismo modo y aunque, como constatan los estudios de derecho comparado, el federalismo fiscal norteamericano ${ }^{66}$, al descansar en la voluntariedad de los Estados, va a ser de todo menos estático ${ }^{67}$ y va a integrar necesariamente ciertas asimetrías, por lo menos desde la década de los sesenta y con la normalización de las interguvernamental relations en el ámbito de las políticas de bienestar, en la cultura constitucional americana se ha asumido la idea de que «no

se, entre otros, LUIS PEÑUELAS I REIXACH, Poder financiero y federalismo en los Estados Unidos, Madrid, 1989, en especial, pp. 89-103; MANUEL MEDINA GUERRERO, La incidencia del sistema de financiación en el ejercicio de las competencias de las comunidades autónomas, Madrid, 1993, pp. 97 y ss; o, el primer capítulo de la monografía de EVA SÁEZ ROYO, Estado social y descentralización política: una perspectiva constitucional comparada de Estados Unidos, Alemania y España, Madrid, 2003.

63 Vid. National Federation of Independent Business v. Sibelius, 567 U. S. _, 49 (2012)

64 Véase, ampliamente, LUIS PEÑUELAS I REIXACH, Poder financiero..., op. cit., p. 157 y ss.

65 STEPHEN HOLMES, CASS R. SUNSTEIN, El costo de los derechos..., op. cit., p. 79

66 Incidiendo en este aspecto, y en comparación con el federalismo fiscal alemán, pueden verse los trabajos de CLIFFORD LARSEN, «States Federal, Financial, Sovereign and Social. A Critical Inquiry into an Alternative to American Financial Federalism», en 47 The American Journal of Comparative Law, Summer, 1999, en especial, pp.473-486; y, «Financial Federalism with an Accent», en 40 South Texas Law Review, Summer, 1999, 737 y ss.

67 Incidiendo en este aspecto, y en comparación con el federalismo fiscal alemán, pueden verse los trabajos de CLIFFORD LARSEN, «Financial Federalism...» op. cit., pp. 758. 
puede obtenerse un tratamiento igualitarios en un amplio territorio sin organismos burocráticos centralizados que creen derechos y los defienda» ${ }^{6}$.

\section{Los derechos sociales en los Estados}

A pesar de la larga trayectoria del federalismo americano, constituye un lugar bastante común el afirmar que el constitucionalismo de los estados no ha alcanzado en los Estados Unidos la mayoría de edad. Un fracaso que se suele vincular a su incapacidad para crear categorías autónomas con respecto al derecho federal, en aquellos ámbitos donde la Constitución federal otorga al Estado y no la federación el poder regulatorio, y donde es, por lo tanto, la Constitución estatal la norma superior de referencia. Este fracaso se puede explicar en parte, como hemos visto, por la creciente proyección del derecho administrativo federal en muchas materias sobre las que, en principio, los Estados tenían titularidad exclusiva, pero que, en la práctica, se han convertido en ámbitos de cooperación federal.

No obstante, como señalan diversos autores, esta falta de autonomía del derecho constitucional de los estados tiene como causa primera la propia amplitud y autoridad moral que adquiere el precedente federal, principalmente a partir de los años de la Corte Warren, lo cual ha provocado que los jueces estatales se hayan acostumbrado a actuar bajo la doctrina judicial federal, de tal forma que en los ámbitos donde éste precedente no exista, el Judicial Review estatal -es decir, utilizando exclusivamente la Constitución estatal como parámetro- va a estar marcado por una especial contención y prudencia ${ }^{69}$. En este sentido, la ausencia -como hemos visto en el primer epígrafe- de un debate moral consolidado en la jurisdicción federal sobre los derechos sociales, ha repercutido sin duda en la propia eficacia de los numerosos derechos sociales que consagran las Constituciones de los Estados ${ }^{70}$.

Hay que decir, con respecto a esto último, que al contrario de la Constitución federal, las constituciones de los estados se asemejan mucho más en este ámbito al constitucionalismo europeo, y consagran todas ellas un amplio y detallado catálogo de derechos de segunda generación. El encaje normativo de estos derechos no exige, por lo tanto, de complicadas exégesis, tal y como vimos que ocurría en el ámbito federal. En este sentido, algunos autores han coincidido en señalar que son muchos los factores que determinan la necesidad de una aproximación judicial diferente

68 STEPHEN HOLMES, CASS R. SUNSTEIN, El costo de los derechos..., op. cit., p. 79

69 Sobre el impacto de la jurisprudencia liberal de la Corte Warren en los jueces estatales, puede verse, por todos, WILLIAM J. BRENNAN, «State Constitutions and the Protection of Individual Rights», 90 Harvard Law Review, 1977, pp. 489-504.

70 Vid. JEFFREY OMAR USMAN, «Good enough for Government Work: The Interpretation of Positive Constitutional Rights in State Constitutions», 73 Albany Law Review, pp. 1491-1492. Igualmente, Helen Hershkoff, ha insisitido en este sentido, en que los jueces de los estados «evitan imponer una concepción material de la vida buena o de la prosperidad» sino que sin distinguirse en esto de los jueces federales, adoptan una rational analysis view especialmente deferente con el principio democrático. Vid. HELEN HERSKOFF, «Positive Rights and the State Constitutions: The Limits of the Federal Rationality Review», 112 Harvard Law Review, April, 1990, pp. 1135-1136. 
a estos derechos en el ámbito estatal. Así, frente al peso que adquiere la objeción contramayoritaria a los derechos sociales en el ámbito federal, factores como la legitimación popular directa de las Constituciones estatales y de sus enmiendas y la propia elección por sufragio de los jueces en muchos estados, disiparían en parte estas objeciones democráticas. Del mismo modo, el carácter detallado de estas constituciones, en tanto instrumentos de gobierno, y la propia facilidad con que puede determinarse el original intent de sus preceptos, constituirían en sí mismos presupuestos para el adecuado self restraint de los jueces. Unas circunstancias a las que habría que añadir la ausencia de los límites propios del federalismo en el ámbito interno de los Estados, es decir, la mayor libertad y plenitud que concede la Constitución americana a los Estados y sus Asambleas en el ámbito de sus poderes legítimos ${ }^{71}$.

El problema, como reconocen distintos autores, es que a pesar de que la especificidad del derecho constitucional estatal ofrece unos presupuestos más favorables a la eficacia judicial de los derechos sociales, la tarea encontrar «remedios presentes o personales» a estos derechos ${ }^{72}$, desde la propia Constitución y sin intermediación de la ley, se enfrenta a las mismas dificultades a las que lo hace la lectura de los derechos sociales como derechos fundamentales en el constitucionalismo europeo. Dificultades que parten de la necesidad de una previa articulación política y consignación presupuestaría para la prestación de los bienes y servicios públicos del bienestar que demandan los ciudadanos, algo para lo cual los jueces no poseen legitimación ni instrumentos necesarios. En este sentido, el propio Tushnet llama la atención sobre el peligro que supone para la misma fuerza normativa de las constituciones estatales, la paulatina tendencia a consagrar en éstas «derechos sociales fuertes» a los que sólo pueden servir «remedios judiciales débiles» ${ }^{73}$. Por otro lado, el reconocimiento de obligaciones sociales con absoluta deferencia hacia legislador en cuanto a su grado de cumplimento, es decir, de meras non self executing provisions, sin preveer ningún tipo de remedio judicial frente a su omisión, podría conducir a diluir la voluntad constituyente en un mero retoricismo, en cierta medida también, lesivo para la fuerza normativa de las constituciones estatales ${ }^{74}$.

Como vemos, por lo tanto, en el nivel de gobierno estatal, el debate sobre la eficacia de los derechos sociales se sitúa en unas coordenadas mucho más próximas al debate europeo. Sin embargo, tal vez, las propuestas doctrinales y mismos ensa-

71 Véase, en extenso, JEFFREY OMAR USMAN, «Good enough for Government Work...», op. cit., pp. 1477-1491; HELEN HERSKOFF, «Positive Rights and the State Constitutions...», op. cit., pp. $1155-1170$.

72 Vid. MARK TUSHNET, «Social Welfare Rights and the...» op. cit., pp. 1909.

73 Vid. MARK TUSHNET, «Social Welfare Rights and the...» op. cit., pp. 1913.

74 Usman establece a este respecto, la siguiente clasificación en cuanto a la forma en la que son interpretados los derechos sociales en las Constituciones estatales, distinguiendo: «los derechos sociales como cuestiones políticas», «como disposiciones sin eficacia directa», «reconocimiento de una obligación con extraordinaria deferencia hacia la asamblea legislativa», o, en las menos ocasiones, y fundamentalmente en el ámbito educativo «como derechos sometidos a un estricto escrutinio». Vid. JEFFREY OMAR USMAN, «Good enough for Government Work...», op. cit., pp. 1491-1506. 
yos judiciales a nivel estatal apuntan a soluciones diferentes, basadas en una suerte de experimentalismo judicial. En este sentido, hay cierta coincidencia en la doctrina cuando se trata de señalar la necesidad de repensar las características de la función judicial a la hora garantizar la acción del legislador estatal en el ámbito de las políticas sociales requeridas por las constituciones de los estados. Así, si bien los jueces no pueden, de forma general, hacer exigibles «aquí»y «ahora» ciertas prestaciones sociales en favor de los ciudadanos, sí pueden llevar a cabo una labor de persuasión, incentivo y control de las otras ramas de gobierno, dentro de la cual, sin erigirse en opresivos agentes contramayoritarios, velen por el cumplimiento de las políticas públicas consignadas por la Constitución y por su propia razonabilidad ${ }^{75}$. En definitiva, las principales decisiones sobre cómo implantar y cuánto gastar en la satisfacción de ciertos derechos sociales consagrados por la Constitución, permanecerían al margen de los jueces, quienes, en última instancia, se limitarían a establecer y garantizar el mínimo de observancia a estos derechos que es exigida por la Constitución. En este sentido, que los jueces asuman un papel activo en el cumplimiento de los principios constitucionales del Welfare State, no significa que este papel haya de ser inquisitivo, a través de un «estricto escrutinio» de las políticas sociales o de su ausencia, sino que puede consistir en un diálogo constitucional con el legislador que no sólo sirva como instrumento puntual de garantía de la Constitución, sino que, al mismo tiempo, consolide una cierta cultura de la responsabilidad en el ámbito del Welfare State.

\section{REFLEXIONES FINALES: EL JUDICIAL REVIEW ANTE EL WELFARE STATE}

Como es sabido, por lo menos desde principios de los años ochenta, la progresiva centralización del federalismo americano se va a encontrar con importantes frentes tanto académicos, como políticos y judiciales. Si la consolidación de una cierta cultura del Welfare State se afirmó en los Estados Unidos a partir de una interpretación de la Constitución favorable a los poderes del Congreso, el libera-

75 En este sentido Tushnet llama la atención sobre el hecho de que los remedios fuertes frente al desconocimiento de los derechos sociales, poseen la innegable virtud de ser visibles e inmediatos, pero pueden generar mucha controversia política, que podrían dar a entender que la reacción de la ciudadanía frente a la ejecución de determinadas políticas sociales exigidas por los jueces, es la verdadera interpretación democrática de los derechos sociales consagrados en la Constitución. Por el contrario, los remedios débiles, basados en el diálogo entre los distintos brazos de gobierno son menos eficaces a corto plazo, pero, en su opinión, mucho más integradores desde el punto de vista político, lo que podría hacerlos más perdurables. Vid. MARK TUSHNET, «Social Welfare Rights and the...»op. cit., en especial, pp. 1917-1918. Desde la premisa de que son las asambleas estatales las mejor posicionadas para valorar las consecuencias fiscales de la extensión de derechos de prestación, el profesor Herskoff defiende igualmente la necesidad de dotar de eficacia a estos derechos, a través de un proceso de diálogo entre el poder judicial y los poderes ejecutivo y legislativo. Vid. HELEN HERSKOFF, «Positive Rights and the State Constitutions...» op. cit., pp. 1189-1191. Véase también, en este mismo sentido, con ejemplos concretos de supervisión judicial de programas sociales por los jueces estatales, OMAR USMAN, «Good enough for Government Work...», op. cit., pp. 1507-1508. 
lismo económico auspiciado por la administración Reagan, va a ir también de la mano de un Nuevo Federalismo que impulse el control del gasto federal y, a su vez, la devolución de competencias a los Estados ${ }^{76}$, alentando así aquellos valores que, para una buena parte de la academia, eran los que constituían la idea original del federalismo, tales como la competencia entre estados, la posibilidad del ciudadano de elegir «con los pies» entre las distintas opciones políticas de los Estados, o el experimentalismo democrático ${ }^{77}$. Del mismo modo, especialmente durante la presidencia del Juez Renhquist ${ }^{78}$, la Corte Suprema va a abandonar la deferencia casi absoluta a favor de federalizing process que había mantenido desde 1937, para afirmar que, más allá de la garantía política que supone la participación de los estados en el proceso legislativo, la Constitución impone ciertos límites materiales a las políticas del Congreso, cuya defensa es competencia ineludible de los jueces. A este respecto, durante este periodo, la Corte Suprema rehabilitará, en cierta medida, la eficacia jurídica de la Décima Enmienda de la Constitución Americana como aticomandering clause, frente a las obligaciones directas impuestas por el Congreso federal a las asambleas y los funcionarios estatales en el ámbito de sus competencias ${ }^{79}$. Asimismo, la Corte reafirmará la vigencia de la doctrina del non-coertion o de las unconstitutional conditions ${ }^{80}$, como límite a aquellas políticas federales de grant in aid que no descansen en un verdadero acuerdo de voluntades con los Estados. Aunque, sin duda, el precedente más representativo de este Nuevo Federalismo que avanza la Corte Suprema es la interpretación de la Commerce Clause que realiza la mayoría del Tribunal en United States v. Lopez ${ }^{81}$. Una sentencia que, si bien no llega a desdibujar la jurisprudencia avanzada por la Corte Suprema desde finales de la década de los treinta, sí restablece, en cierta medida, la autoridad de los jueces para controlar las leyes aprobadas por el Congreso bajo la Commerce Clause y, en concreto, para valorar de una manera diferente a como lo ha hecho el legislador, si la actividad regulada tiene o no verdaderamente un efecto sustancial en el comercio interestatal ${ }^{82}$.

76 De entre los distintos trabajos que analizan la envergadura real, desde el punto de vista financiero, de este proceso de devolución de responsabilidad a los Estados, pueden verse los dos libros de TIMOTHY CONLAN, New Federalism, Intergovernmental Reform from Nixon to Reagan, Washington, 1988, en especial, pp. 93 y ss; y From New Federalism to Devolution. Twenty-Five Years of Intergovermental Reform, Washington, 1998, que constituye una actualización del primero.

77 Entre otros muchos, puede leerse una defensa originalista de estos valores en MICHAEL McCONNELL, «Federalism: Evaluating the Founders' Desing», 54 University of Chicago Law Review, 1987, pp. 1484 y ss.

78 Vid. SUE DAVIS, Justice Rehnquist and the Constitution, Priceton, New Jersey, 1989, pp. 135-188.

79 New York v. United States, 505 U. S. 144 (1992) y Mack and Printz v. United States, 521 U. S. 898 (1997)

80 Vid. KATHLEEN M. SULLIVAN, «Unconstitutional Conditions», 102 Harvard Law Review, May 1989, en especial, pp. 1429-1430 y 1461-1462.

81 United States v. Alfonso Lopez, Jr., 514 U. S. 549 (1995)

82 Puede verse, entre otros, DONALD H. REGAN, «How to Think About the Federal Commerce Power and Incidentally Rewrite United States v. Lopez», 94 Michigan Law Review554, 1995, pp. 555; ANN ALTOHUSE, «Enforcing Federalism After United States v. Lopez», 38 Arizona Law Review 793, 1996, pp. 817. En la doctrina española, véase, FERNANDO REY, United States v. López y el «Nuevo federalismo norteamericano», Revista Española de Derecho Constitucional, n. ${ }^{\circ}$ 51, Septiembre-Diciembre, 1997, pp. 297. 
Ahora bien, si nos preguntamos, en concreto, hasta qué punto este replanteamiento general de los límites a los poderes del Congreso afecta a los presupuestos jurídicos desde los cuáles se ha afirmado en los Estados Unidos el Welfare State, lo cierto es que, desde 1937 hasta la fecha, la Corte Suprema nunca ha declarado contrario a la Constitución ningún programa federal de carácter social. En este sentido, en principio, los presupuestos jurídicos que hicieron posible esa idea de Estado Social en los Estados Unidos permanecerían intactos. La prueba evidente de ello debería de ser, en principio, el hecho de la que la Corte Suprema en su sentencia National Federation of Independent Business $v$. Sebelius ${ }^{83}$ haya avalado recientemente la constitucionalidad del que puede considerarse uno de los más ambiciosos y probablemente el más costoso de los programas sociales de la historia del país, como es la reforma sanitaria emprendida por Obama ${ }^{84}$. Sin embargo, leída la sentencia, esta afirmación parece precipitada. Por ello, a pesar de que esta decisión requiere sin duda un lugar a parte y no puede ser abordada en profundidad en este trabajo, creo que, al hilo de lo que se viene exponiendo, hay ciertos aspectos de la misma cuya mención no puede ser eludida y cuyo comentario nos puede servir como reflexión final.

En NFIB v Sebelius la Corte Suprema ha afirmado que la Commerce Clause no legitima al Congreso para imponer a los ciudadanos el mandato de adquirir un seguro médico ${ }^{85}$, por mucho que pueda considerar que ésta es una medida adecuada para afrontar uno de los principales problemas económicos del país, como es el gran número de personas que viven sin seguro y el número de bancarrotas y gastos médicos sin cubrir que estas producen cuando padecen alguna enfermedad o acci-

83 National Federation of Independent Business v. Sebelius, 567 U. S. _ (2012) El texto de la reforma fue firmado por el Presidente Obama el 10 de marzo de 2010 con el nombre de ThePatient Protection and Affordable Care Act

84 Un importante sector de la doctrina norteamericana defendió la constitucionalidad de la reforma. Entre la ingente literatura vertida al respecto, pueden destacarse las contribuciones de LAURENCE H. TRIBE, «The Constitutionality of the Patient Protection and the Affordable Care Act: Swimming in the Stream of Commerce», 35 Harvard Journal of Law and Public Policy, summer 2012; ANDREW KOPPELMAN, «Bad News for Mail Roberts: The Obvious Constitutionality of Health Care Reform», 121 Yale Law Journal Online, April 26, 2011; ERWIN CHEMERINSKY, «A defense of the Individual Mandate», 62 Mercer Law Review 605, Winter, 2011; RONALD DWORKIN, «Why Health Care Challenge is Wrong», The New York Review of Books, 2 April, 2012; MARK A. HALL, «Commerce Clause Challenges to Health Care Reform», 159 University of Pennsylvania Law Review, June, 2011; DAVID ORENTLICHER, "Constitutional Challenges to the Health Care Mandate: Based in Politics, not Law», 160 University of Pennsylvania Law Review 19, 2011; GUILLIAM METZGER, «Defense of the Constitutionality of Health Care Reform», 62 Mercer Law Review 605, Winter, 2011.

85 El mandato individual constituye el elemento clave sobre el que pivota el conjunto de la reforma. En virtud del mismo, todos los ciudadanos estadounidenses deben de adquirir un mínimo de cobertura sanitaria en el mercado privado de las aseguradoras, de tal forma que aquellos que en el año 2014 no hayan adquirido esta cobertura tendrán que pagar lo que en principio fue entendido como una «sanción», que sería recaudada por el Gobierno Federal a través de los mismos mecanismos que son usados para la recaudación de impuestos. Como correlato lógico a este mandato, la ley prohíbe a las aseguradoras denegar la adquisición del seguro médico o incrementar las primas a aquellas personas que presenten condiciones previas que les hagan más susceptibles de requerir tratamiento médico. Patient Protection and Affordable Care Act, Sec. 1501 
dente. Para la Corte Suprema la Commerce Clause legitima al Congreso para regular una actividad pero no para imponer la misma, tal y como pretendía el legislador al introducir el mandato individual de adquirir un seguro ${ }^{86}$.

Del mismo modo, la mayoría del Tribunal entiende que la Necessary and Proper Clause legitima al Congreso para establecer esta obligación de adquirir un seguro, en tanto medida adecuada para conseguir un fin que la Constitución encomienda al Gobierno Federal bajo la Commerce Clause, como sería la regulación mercado de las aseguradoras sanitarias. De este modo, la Corte Suprema reduce, de una forma casi radical, la amplitud con la que hasta entonces se había entendido la doctrina de los poderes implícitos desde McCulloch v. Maryland. Así, antes de valorar si una determinada política federal puede considerarse necesaria o adecuada para realizar alguno de los poderes que la Constitución reserva al Gobierno federal y, por lo tanto, amparada por la Necessary and Proper Clause, hay que descartar, previamente, que esta política del Gobierno Federal forme parte de los atributos de la soberanía reservada por la Constitución a los estados, es decir, que la misma constituya no un poder implícito sino, realmente, «un poder independiente y sustantivo» que el Congreso sólo podría ejercer de haberse enumerado a su favor en la Constitución ${ }^{87}$.

Finalmente, para la mayoría del Tribunal, los mecanismos de persuasión financiera que había usado el Congreso de cara a favorecer la participación de los Estados en la reforma sanitaria, no podían estar amparados por la Welfare Clause por su carácter coercitivo ${ }^{88}$. La razón de ello es que los perjuicios económicos que tendrían que afrontar los estados que decidieran mantenerse al margen de la reforma eran tan gravosos que no podía considerarse realmente que el programa dejara una posibilidad a los Estados para decidir no participar. En definitiva, el incentivo financiero constituía en sí mimo un instrumento de coacción, incompatible con la separación de poderes entre los Estados y la Federación que establece la Constitución ${ }^{89}$.

A pesar de que el Tribunal corrige al Congreso en todos los fundamentos sobre los que éste quiso hacer descansar su legitimidad para acometer la reforma, final-

86 National Federation of Independent Business v. Sibelius, 567 U. S._, 23, 24 (2012)

87 National Federation of Independent Business v. Sibelius, 567 U. S. _, 33 (2012)

88 La reforma sanitaria lleva a cabo una significativa extensión del principal programa federal de ayuda a los estados para la protección del derecho a la salud hasta entonces existente, el conocido Medicaid, promovido en los años sesenta por el presidente Lyndon Jonhson, y que había tenido como beneficiarios a las familias necesitadas, niños, y personas que padeciesen algún tipo de discapacidad. En realidad, a excepción hecha de estos supuestos de deficiencias físicas, se puede decir que el Medicaid era un programa concebido para ayudar principalmente a las familias. A este respecto, la gran novedad que introduce la reforma sanitaria es que se extiende el ámbito de beneficiarios del Medicaid, incluyendo en él a aquellos adultos sin hijos cuyo nivel de renta se encuentre por debajo del $138 \%$ del umbral de la pobreza que haya sido establecido. Dado que con ello el espectro de beneficiarios por el programa se ampliaba considerablemente, la reforma también va a prever un incremento en la financiación federal que recibirán los estados para su implementación. Ahora bien, para asegurarse la cooperación estatal, la ley establecía que aquellos estados que decidan no atender a la extensión del ámbito de beneficiarios debían de ser excluidos, no sólo el incremento presupuestario que el Gobierno Federal destine a la atención de estos nuevos colectivos, sino también de toda la financiación federal que hasta ese momento percibían a través del Medicaid. Patient Protection and Affordable Care Act, Sec. 2005

89 National Federation of Independent Business v. Sibelius, 567 U. S. _, 54 (2012) 
mente, la mayoría de sus miembros avaló la constitucionalidad de prácticamente la totalidad de la reforma legislativa, buscando para ello un fundamento legítimo a la acción del Congreso en base a otros principios constitucionales ${ }^{90}$. Como decíamos, desde la década de los treinta, la Corte Suprema nunca había tumbado ningún programa social federal y esta no iba a ser la ocasión. El pedigrí democrático de esta reforma y la crisis de legitimidad frente a la opinión pública que desde Bush v. Gore arrastra el Tribunal, pesaron seguramente mucho sobre el presidente Roberts ${ }^{91}$, quien era muy consciente del difícil encaje social que tendría una decisión por cinco a cuatro que echara por tierra lo que para algunos constituía un precedente democrático de interpretación de la Constitución ${ }^{92}$.

En cualquier caso, lo que creo que no se puede desconocer es que esta sentencia, desde un punto de vista teórico, no sólo consolida sino que, en gran medida, avanza en la línea de interpretación del federalismo marcada por la Corte Renhquist, caracterizada por la recuperación de espacios de indemnidad a favor de los Estados, en base a un lectura restrictiva de los poderes del Congreso. Si la teoría que hace posible la conformación del Welfare State americano descansaba en una interpretación muy laxa de los poderes conferidos al Congreso por la Commerce Clause, la Welfare Clause y la Necessary and Proper Clause, creo que ha de reconocerse que la sentencia NFIB $v$. Sibelius supone un precedente restrictivo de las futuras posibilidades

90 Concretamente, la Corte considera que si bien el Congreso no puede imponer el mandato individual de adquirir un seguro médico a los ciudadanos, si puede gravar la conducta de quien no lo haga, en base al poder de establecer y recaudar impuestos que le concede la Tax Power Clause del artículo primero de la Constitución. Para la Corte, este impuesto sobre los no asegurados no tendría la naturaleza de una sanción, sino que se trataría de un uso de los instrumentos impositivos del estado con el legítimo fin de incentivar una conducta, en este caso, la de adquirir un seguro médico en el mercado de las aseguradoras privadas. Con respecto a las sanciones económicas que sufrirían los Estados que decidiesen no participar en la extensión del Medicaid que plantea la reforma, la Corte las deja sin efecto por su carácter coercitivo, pero mantiene en vigor el resto del programa, ofreciendo a los Estados la opción o bien de participar en el nuevo programa, o bien de mantenerse en el Medicaid en los términos que hubieran acordado con la administración federal. National Federation of Independent Business v. Sibelius, 567 U. S. _, 54 (2012)

91 Vid. RONALD DWORKIN, «Why Did Roberts Change His Mind?» The New York Review of Books, 9 july, 2012. Los profesores Geoffrey R. Stone y Jane Dailey, apuntaron también, en el Huffingtonpost, el importante carácter simbólico del voto del presidente Roberts en este caso. En su opinión, desde la sentencia de Bush v. Gore la Corte había ido perdiendo paulatinamente todo el prestigio asociado a su neutralidad, al haberse consolidado de forma casi inamovible una mayoría de 5-4 a favor de los jueces conservadores, en todos los litigios que revestían un particular significado político. Con el juicio del Affordable Care Act, el juez Robberts habría aprovechado, en su opinión, la última oportunidad para liberarse de esta inercia y de paso salvar a la Corte de un rechazo popular que situara su posición institucional en uno de los momentos más complicados de su historia. GEOFFREY R. STONE \&JANE DAILEY, «Savaging Roberts: Conservatives Run Amok», HUFFINGTON POST (July 3, 2012, 7:59 PM), http://www.huffingtonpost. com/geoffrey-r-stone/savaging-roberts-conserva_b_1647980.html; En sentido muy critic con la «declinación» del Juez Roberts, puede verse, RICHARD A. EPSTEIN, «What Was Roberts Thinking?» en Defining Ideas, Hoover Institution Journal, Stanford University, disponible en http://www.hoover.org/publications/ defining-ideas/article/121426;

92 Vid. BEATRIX HOFFMAN, «Health Care Reform and Social Movements in the United States», American Journal ofPublic Health, January 2003, Vol 93, No. 1; REBECCA E. ZIETLOW, «Democratic constitutionalism and the Affordable Care Act», 72 Obio State Law Journal, pp. 1372-1376. 
de avanzar, desde Gobierno Federal, en la consolidación de un marco normativo y también económico común del bienestar.

En su voto particular a Goldberg v. Kelly, el juez Black afirmaba que dado que el Welfare State en los Estados Unidos no era un mandato constitucional sino un experimento y que, por lo tanto, la Corte debía de mantenerse al margen, para permitir que la experiencia de los derechos sociales fuera una experiencia democrática ${ }^{93}$. El alegato de Black, recogía en gran medida el guante lanzado por el Juez Holmes en Lochner y constituye, en otro contexto, una llamada de atención a la mayoría del Tribunal sobre las patologías democráticas que presentaba su (a la postre frustrado) ensayo de deducir derechos de prestación de la Enmienda XIV. Sin embargo, creo que las palabras de Black adquieren también sentido en supuestos como NFIB $v$. Sebelius, en el que el Tribunal tiene que juzgar una ley de la cual va a depender, en la práctica, la extensión de una cobertura social esencial, como es la asistencia médica, a la práctica totalidad de los ciudadanos del país.

Al contrario que en otras experiencias federales donde la tendencia ha sido centrífuga, como se ha visto, la construcción del Estado Social en los Estados Unidos ha corrido paralela al fortalecimiento jurídico del poder central. No se quiere decir con esto que pueda establecerse un nexo causal entre centralización y bienestar, pero sí puede decirse que, por lo menos desde un punto de vista empírico, y más allá de que el bienestar en el federalismo americano tenga una geometría variable, el Welfare State se hizo posible en los Estados Unidos a partir de una interpretación centralista de la Constitución.

En este sentido, creo que no puede obviarse la dimensión moral que adquiere el Judicial Review en determinados contextos normativos donde, bajo las categorías del federalismo, lo que se está defendiendo, en realidad, es la extensión y la garantía de determinados ámbitos del bienestar. Creo que es evidente, si uno se fija, por ejemplo, en el debate académico sobre la reforma sanitaria que, de la misma forma que quienes defendían una interpretación laxa de los poderes del Congreso bajo la Commerce Clause estaban al mismo tiempo defendiendo una determinada comprensión del papel del Estado con respecto a la sociedad; aquellos que reclamaban un espacio de indemnidad a favor de los estados, lo hacían también, en muchos supuestos, con propósitos puramente libertarios ${ }^{94}$. Así, en cierta medida, dado que desde el fin de la doctrina Lochner, la cláusula del debido proceso no puede erigirse en un límite frente a leyes que regulen la actividad económica de los ciudadanos, una vi-

93 Goldberg v. Kelly, 397 U. S. 254, 272 (1970) (Black dissenting)

94 Dentro de esta línea doctrinal podríamos situar, entre otros muchos, los trabajos de RICHARD A. EPSTEIN, «ObamaCare vs. The Commerce Clause» en Defining Ideas, Hoover Institution Journal, Stanford University, disponible en http://www.hoover.org/publications/defining-ideas/article/100456. PAUL CLEMENT, «The Patient Protection and Affordable Care Act and Breadth and Depth of Federal Power», 35 Harvard Journal of Law E Public Policy 887, Summer, 2012. RANDY E. BARNETT, «Turning Citizens into Subjects: Why the Health Insurance Mandate is Unconstitutional», 62 Mercer Law Review 605, Winter, 2011, pp. 608-609; GARY LAWSON, DAVID B. KOPEL, «Bad News for Professor Koppelman: The Incidental Unconstitutionality of The Individual Mandate», 121 Yale Law Journal Online 267, en especial, pp. 281-283 y 287 y ss. 
sión restrictiva de los poderes conferidos al Gobierno Federal puede servir, no sólo como garantía de los derechos originales de los Estados, sino también para eximir a los ciudadanos del cumplimiento de las obligaciones derivadas de los programas federales. En este sentido, dado que el Welfare State en los Estados Unidos se sustenta en gran medida en una comprensión determinada de los poderes del Congreso, parece difícil que remover judicialmente esta comprensión no tenga efectos sobre la propia cultura del bienestar y su desarrollo futuro. Por ello, la idea de que el Judicial Review presenta patologías contramayoritarias cuando los jueces revisan las leyes que afectan a derechos fundamentales, pero no cuando aplican las reglas de distribución del poder entre los estados y la federación, es difícil de sostener, por lo menos con carácter general ${ }^{95}$.

En definitiva, y por concluir, la formación del Welfare State en los Estados Unidos pone de manifiesto que las normas de distribución del poder propias del federalismo, son normas abiertas a la interpretación democrática, y que por ello, indefectiblemente, adquieren una significación moral. En este sentido, lejos de ser reglas constitucionales, en muchos escenarios las categorías del federalismo operan judicialmente como los principios esencialmente controvertidos ${ }^{96}$ de los que hablara Waldron, motivo por el cual, desde el punto de vista democrático, demandan para su aplicación, una especial deferencia hacia la interpretación acordada por los representantes de los ciudadanos y de los Estados a través de la ley federal.

$* * *$

TITLE: Welfare State and Judicial Review.

AвSTRACT: This paper addresses the evolution of the Welfare State in American Federalism, highlighting the role played by Judicial Review. With such an aim, we first study the causes of the so-called "American Exceptionalism", in reference to the lack of constitutional enforcement of social rights. Concretely, we will focus on the frustrated attempts of the Supreme Court to give efficacy to certain social rights through the Fourteenth Amendment of the Federal Constitution. Once this exception and its reasons are fully acknowledged, we are able to discuss how the construction of the welfare state in the United States, since the New Deal to the present day, has been accompanied by an interpretation of Federal categories very favourable to the powers of the National Congress. Similarly, we will analyse the limitations that state judges have when enforcing social rights protected in state constitutions as well as the current debate taking place at the state level regarding possible reformulations of the judicial function when it comes to implement provisions of social nature that require public policies. Finally, and in light of the recent case law of the Supreme Court, we will insist on the necessary judicial deference in cases in which Federal categories are used to implement new welfare goals.

ReSUMEN: En este trabajo se lleva a cabo una aproximación a la evolución del Estado Social en el Federalismo americano, destacando el papel que ha tenido en la misma el Judicial Review. Para ello, primeramente, se estudiarán las causas del denominado excepcionalismo americano, en lo referido a la falta de consagración constitucional de los derechos sociales. Se estudiarán aquí los frustrados intentos de la Corte Suprema de dotar de eficacia a ciertos derechos sociales a partir de la Enmienda Catorce. Una vez señalada esta excepción americana,

95 En sentido contrario, véase, STEVEN G. CALABRESI, «Democracy and Disdain. In response to Pamela S. Karlam», 126 Harvard Law Review, 2012, p. 14

96 JEREMY WALDRON, «Vagueness in Law and Language: Some Philosophical Issues», 82 California Law Review, 509, 1994, 526-540. 
se analizará cómo la construcción de un estado del bienestar en los Estados Unidos, desde el New Deal hasta nuestros días, ha ido de la mano de una interpretación de las categorías del federalismo favorable a los poderes del Congreso. Del mismo modo, se llamará la atención sobre las limitación que tienen los jueces estatales para dar eficacia a los derechos sociales de sus constituciones y de cómo a nivel estatal, se abre paso la idea de reformular la función judicial cuando se trata de aplicar disposiciones de carácter social que exigen políticas públicas. Finalmente, y a la luz de la última jurisprudencia de la Corte Suprema, se insistirá en la necesaria deferencia judicial que reclaman las leyes estatales que sobre una interpretación concreta del federalismo implementan nuevas facetas del bienestar social.

KeY wORDS: Federalism USA; Welfare State; Social Rights; Judicial Review.

Palabras Clave: Federalismo USA; Estado Social; Derechos Sociales; Control de Constitucionalidad. 